\title{
1 Does range expansion modify trait covariation? A study of a northward expanding
}

\section{2 dragonfly}

3

$4 \quad$ Allan Raffard ${ }^{1,2^{*}}$, Lieven Therry ${ }^{1 *}$, Fia Finn ${ }^{1,3,4}$, Kamilla Koch $^{5}$, Tomas Brodin ${ }^{6}$, Simon 5 Blanchet ${ }^{1,7}$ and Julien Cote 7* $^{*}$

6

$7{ }^{1}$ Centre Nationale pour la Recherche Scientifique (CNRS), Université Paul Sabatier (UPS);

8 Station d'Écologie Théorique et Expérimentale, UMR 5321, Moulis 09200, France

$9 \quad{ }^{2}$ EcoLab, Université de Toulouse, CNRS, INPT, UPS, 31062 Toulouse, France

$10{ }^{3}$ Department of Aquaculture and Fish Biology, Hólar University College, Háeyri 1,

11 Sauðárkrókur IS-550, Iceland

$12{ }^{4}$ Institute of Life and Environmental Science, University of Iceland, Sturlugata 7, Reykjavík

13 IS-101, Iceland

$14{ }^{5}$ Department of Evolutionary Ecology, Johannes Gutenberg-University Mainz, Mainz 55131,

15 Germany

$16{ }^{6}$ Department of Ecology and Environmental Science, Umeå University, Umeå 90187,

17 Sweden

$18{ }^{7}$ CNRS, UPS, IRD; Laboratoire Évolution et Diversité Biologique, UMR 5174, Toulouse

1931062 , Cedex 9, France

20

$21 *$ denotes co-first authors

22 Corresponding author: Allan Raffard, allanraffard@outlook.com

ORCID ID: https://orcid.org/0000-0002-4453-5969

Author Contributions: LT, FF, SB and JC conceived and designed the experiment. LT, FF and KK conducted fieldwork and performed the experiment. LT and AR analyzed the data with input from SB and JC. LT wrote the first draft, AR wrote the revised version and all authors contributed to these versions. 


\section{Abstract}

25 The adaptive value of correlations among phenotypic traits depends on the prevailing

26 environmental conditions. Differences in selection pressures during species range expansions

27 may therefore shape phenotypic integration. In this study, we assessed variation in behavioral

28 and morphological traits, as well as their covariations, in replicated southern and northern

29 European populations of the northward expanding dragonfly Crocothemis erythraea. Larvae

30 from northern populations were, on average, darker in color, and therefore, better

31 camouflaged than larvae from southern populations. However, there was no difference in

32 activity level. Darkness and activity were positively correlated in larvae from northern

33 populations, whereas this trait covariation was missing in southern populations. These

34 findings indicate the emergence of alternative strategies in time-limited northern populations, 35 a higher activity level that required better camouflage through darker coloration, while less

36 active larvae benefited from an energy-saving strategy by reducing the investment in costly

37 traits, such as body darkness. We further found that larger larvae emerged into larger adults,

38 with a higher investment in flight morphology. Our findings imply that phenotypic

39 integration is associated with the northward range shift, potentially differentially shaping

40 fitness consequences, and ecological interactions in southern versus northern populations.

41 Keywords: behavior, climate change, colonization, growth-predation trade-off, phenotypic

42 architecture, range expansion 


\section{Introduction}

44 Distributions of many species are currently shifting, triggered by climate change (Chen et al. 2011) and human-assisted introductions of non-native species (García-de-Lomas and Vilà 2015). Shifts in the distribution of species often go along with differences in phenotypic traits

47 (reviewed by Chuang and Peterson 2016), whereby individuals in newly colonized areas typically show, for example, greater dispersal ability, reproductive investment, or levels of foraging activity, which lead to a faster pace of life, compared with their counterparts in longestablished populations (e.g., Hill et al. 2011; Pintor et al. 2008; Therry et al. 2014a,b,c, 2015). Two main non-exclusive mechanisms can explain this phenotypic change. First, dispersers are a non-random subset of individuals from the source populations that are characterized by a set of traits that favor a better colonization capacity, which includes, for example, high risk-taking behavior and metabolic rate (Cote et al. 2010; Carere and Gherardi 2013). Second, range limits are shaped by a complex interplay of abiotic and biotic factors (reviewed in Gaston 2009), with conditions at species' range edges being often more stressful than those in core populations (Hardie and Hutchings 2010), which may shape organism phenotype through plasticity or selection. For instance, during northward range expansions, organisms face strong shifts in climatic conditions. Ectotherms at higher latitudes are often darker in color (i.e., a higher level of melanism), which is advantageous for thermoregulation at lower temperatures (Clusella Trullas et al. 2007).

While a growing number of studies documented changes in morphological, physiological, and behavioral traits at the range expansion front (Zeuss et al. 2014; Chuang and Peterson 2016; and references therein), none of these studies, according to our knowledge, focused on changes in covariations among phenotypic traits (i.e., phenotypic integration; Kim and Vellando 2015). Determining changes in phenotypic integration during range expansion is required for understanding the evolutionary constraints and the proximate basis of changes in 
single traits during range expansion. The impact of a phenotypic trait on fitness indeed often depends on the value of another trait, resulting in correlational selection, which can lead to adaptive trait covariation (Roff and Fairbairn 2012). Therefore, the covariation among traits will vary with local environmental conditions that shape the selection pressures on correlated traits (Endler 1995; Bell and Sih 2007; Dingemanse et al. 2007; Raffard et al. 2019). Since environmental conditions, and therefore, selection pressures typically differ between core and expanding edge populations (Hardie and Hutchings 2010; Phillips et al. 2010), trait covariations are likely to vary between core and marginal populations.

$$
\text { In particular, ectotherms have evolved morphological and behavioral traits that allow them }
$$
to cope with different conditions at higher latitudes, such as climatic conditions or season length. For example, species and individuals are often darker in color and larger in colder environments compared to warmer environments (Zeuss et al. 2010) or have faster growth rates at higher latitudes due to time constraints (Therry et al. 2014a). An investment in body size or a fast growth rate generates higher energetic needs and forces individuals to have higher foraging activity, increasing predation risk (growth-predation trade-off; Werner and Anholt 1993; Stamps 2007). Therefore, predation can lead to correlational selection between body size, exploratory or activity behaviors, and anti-predator defense traits (Dingemanse et al. 2007; Raffard et al. 2019). For example, risk-taking juvenile three-spined sticklebacks (Gasterosteus aculeatus) are better camouflaged through darker body coloration compared to risk-adverse juveniles (Kim and Velando 2015), and this covariation may be the result of selection pressures induced by predators in the environment (Dingemanse et al. 2007). Trait covariations can also result from pleiotropic effects, linkage disequilibrium between genes, and similar plastic responses to conditions among traits. For example, body darkness in invertebrates often correlates with behavioral traits and immune function, whereby darker individuals are more active, explorative, and bold or possess a higher immune defense 
93 (Verhoog et al. 1998; Armitage and Siva-Jothy 2005; Mafli et al. 2011). Cuticular

94 melanization occurs via the phenoloxidase cascade, which plays a key role in immune

95 responses (González-Santoyo and Córdoba-Aguilar 2012), and dopamine is a

neurotransmitter produced as an intermediate of the melanization pathway that influences behavior (Hodgetts and O'Keefe 2006).

In this study, we investigated the phenotypic variation and covariation across southern and more recently colonized areas in northern Europe of a range-expanding dragonfly

(Crocothemis erythraea). We measured multiple phenotypic traits in larval and adult stages (activity, body size, and coloration), to fulfill three specific objectives. First, we tested differences in the mean value, variation among individuals, and variation within individuals (i.e., repeatability and plasticity between life stages and thermal conditions) of phenotype between southern (i.e., core) and more northern (i.e., edge) populations. We expect individuals from populations in northern Europe to exhibit higher activity, darker coloration, and larger body size than individuals from southern populations due to higher dispersal and thermoregulation capacity. Furthermore, we expect higher temperature-induced behavioral plasticity in younger populations at higher latitudes since phenotypic plasticity has been associated with the invasive potential of populations and evolves upwards during range expansion (Aubret and Shine 2009; Chevin et al. 2010; Valiente et al. 2010). Second, we tested whether phenotypic covariations differ between southern and northern populations and at different life stages. Notably, activity, body size, and coloration should be correlated if correlations lead to higher adaptive values. For example, active individuals may display darker colorations to be better camouflaged for predators while foraging. Also, we expect that the enhanced growth-predation trade-off in the northern populations translates into a stronger covariation among traits associated with food acquirement (activity) and anti-predator defense (coloration). Finally, we tested a potential carry-over of phenotypic traits from the 
118 larval to the adult stage to predict whether potentially observed differences among

119 populations would translate into fitness differences in adults.

120

\section{Material and Methods}

122 To achieve our objectives, we collected larvae from four South-European and five north-

123 European populations, and we scored larval behavioral traits (activity) at cold $\left(19{ }^{\circ} \mathrm{C}\right)$ and

124 warm $\left(25^{\circ} \mathrm{C}\right)$ temperatures. It allowed us to test the differentiation of both behavioral types

125 and behavioral reaction norms in response to a major environmental condition that varies

126 along the expansion gradient (we expected colder temperatures in northern populations).

127 After behavioral tests, we quantified larval darkness and size. Then, the larvae were reared in 128 a common garden until adulthood to quantify similar traits (adult darkness, adult size, and 129 relative thorax length) at the reproductive life stage. We focused on the risky behaviors 130 associated with food acquirement (activity) and anti-predator defense (camouflage through

131 higher body darkness, True 2003) since it has been shown that patterns of phenotypic

132 integration depend on predation regimes (Dingemanse et al. 2007).

134 Study system, collection, and housing

135 Crocothemis erythraea (Brullé, 1832) is a dragonfly species with a predominantly African 136 distribution, with its European native breeding range confined to the Mediterranean (Dijkstra

137 2006). In the 1960s, a climate-driven northward range expansion through Europe started from 138 southern populations (Ott 2007). The southern populations belong to the central European 139 distribution area colonized in the 80s. In the 1980s, the species had colonized the entire

140 France, although with a patchy distribution and only low-density populations in regions north 141 of the Loire River (Dommanget 1987). The species further colonized northern Europe in the 
next decades (Ott 2007), with the northernmost populations currently located in Northern

143 Germany (Brockhaus et al. 2015).

144 The species breeds in a wide range of stagnant water habitats and seeks out warmer

145 microclimates in the north, predominantly shallow waters with dense aquatic vegetation

146 (Dijkstra 2006). We studied four southern populations from Southern France (S1: Bram, S2:

147 Camargue, S3: Albi, and S4: Brenne) and five northern populations from North-West Europe

148 (N1: Mainz, Germany; N2: Ghent, Belgium; N3: Soerendonk, The Netherlands; N4:

149 Dortmund, Germany; and N5: Braunschweig, Germany). Populations S4, N1, N2, and N4

150 consist of 2 subpopulations located $<25 \mathrm{~km}$ from each other [Electronic Supplementary

151 Material (ESM) A; Table S1 and Fig. S1], and were pooled in the analyses. The first

152 reproductions in the region of Mainz and Ghent were observed in the early 1990s (Deknijf

153 1995, Ott 2007), near Dortmund in 1995 (Bauhus 1996), and up to latitudes of Braunschweig

154 in 2000 (Lohr 2003).

155 Larvae of C. erythraea in the penultimate and last larval instars were collected in the field

156 using an aquatic kick net between 12 May and 22 June 2015 and transported to the laboratory

157 (see ESM A for sample dates per population). Larvae were housed individually in $300 \mathrm{ml}$ 158 opaque vials filled with dechlorinated tap water and daily fed with ad libitum chironomid

159 larvae. The vials were kept in an incubator at $22^{\circ} \mathrm{C}$ and a 15.5:8.5 L:D photoperiod. Larvae

160 were housed on average for $18.7 \pm 8.3(\mathrm{SD})$ days in the incubators under controlled

161 laboratory conditions before the start of the behavioral trials.

162

163

Experimental set-up

164 Behaviors of 220 larvae (southern: 104; northern: 116) in the last larval instar were tested at 165 both $19{ }^{\circ} \mathrm{C}$ (low-temperature treatment) and $25^{\circ} \mathrm{C}$ (high-temperature treatment). Tests were 166 performed at 24-hours intervals between the tested temperatures (see ESM A for sample size 
per population). Half of the larvae per population were first tested at low temperature, while the other half was first analyzed at high temperature (testing order). To standardize conditions among individuals, larvae were deprived of food and acclimatized to testing temperatures for 20 hours before the start of each behavioral assay. At the initiation of the test, each larva was introduced in the center of a white plastic tray $(30 \mathrm{~cm} \times 20 \mathrm{~cm})$ filled with $2 \mathrm{~cm}$ dechlorinated tap water. The activity of each larva in the experimental arena was recorded for 200 minutes, with webcams connected to a computer with the iSpy® software (version 6.3). Twenty larvae were tested at the same time using 20 arenas (arena ID), and larvae of different range locations (southern vs. northern) were simultaneously tested, and their positions among the 20 arenas were randomized. We extracted the total distance moved (activity) from the video recordings using the Ethovision ${ }^{\circledR}$ software (version XT8). Due to the poor quality of some videos, behavioral scores of 76 larvae (southern: 35; northern: 41 - cold treatment: 33; warm treatment: 43) were obtained in only one of the two temperatures analyzed (i.e., $17 \%$ of trials).

After the second behavioral trial, larvae were photographed (dorsal side) in the laboratory using a Canon Powershot G16 ${ }^{\circledR}$. To performed this, larvae were gently blotted dry with absorbent tissue and placed on a white background with standardized light conditions (i.e., in the same place and with the same light intensity). Larval head width and body darkness were quantified using the ImageJ ${ }^{\circledR}$ (vs. 1.51) software. Head width was used as a proxy for larval size (Benke 1970), and body darkness was used as a proxy for cuticle melanization (Fedorka et al. 2013). We measured the darkness of the dorsal areas of thorax and abdomen by quantifying (using ImageJ) the level of grey value presents in the selected areas. The ImageJ software produces a mean grey score for selected pixels (from $0=$ totally black to $255=$ totally white). We removed the grey value from a control blank to correct for a potential session effect (i.e., the grey value of control blank minus the grey value of the sample). The 
control value was the average of the mean grey values of three pictures of a white piece of paper (for each session) placed behind the larvae. Higher levels of grey value correspond to higher darkness (from 92.2 to 156.2, Mean $=125.0$, Variance $=140.5$ ). Then, larvae were placed back in their original breeding vials and reared until the adults emerged. Forty-three percent of the larvae survived until the adult stage $(\mathrm{N}=96$; see ESM A for sample size per population). When the adult exoskeleton had hardened, 24 hours after emerging at $22{ }^{\circ} \mathrm{C}$, a picture of the dorsal side of the adult was taken using a Canon Lide 210 scanner ${ }^{\circledR}$ and a picture of the lateral side of the adult was taken using a Canon Powershot G16 ${ }^{\circledR}$. The darkness of the dorsal area of thorax and abdomen was measured using the dorsal picture with the method described for larval darkness quantification. The length of the thorax (from the junction of pronotum and thorax to the caudal attachment of the hind wing with the thorax) and the length of the abdomen (from the caudal attachment of the hind wing with the thorax to the caudal end of the abdomen) were measured on the lateral picture. The total length was calculated as the sum of thorax and abdomen length, and the relative thorax length (RTL) was calculated as the ratio between the thorax length and the total length. The relative thorax length is correlated with flight muscle mass in odonates (Therry et al. 2015), and greater investment in flight muscle mass has been associated with greater flight performance in insects (Schilder and Marden 2004; Therry et al. 2014c).

210

211 Statistical analyses

\section{Phenotypic differentiation between southern and northern individuals}

213 We analyzed the effect of range location (southern vs. northern, assuming that northern areas correspond to edge habitats, whereas southern areas could be seen as core habitats) on larval activity, larval darkness, larval size, adult darkness, adult size, and relative thorax length using linear mixed models. We ran these analyses with range location instead of latitudes for 
the sake of comparison with the covariation analyses (i.e., Structural Equation Modeling,

218 SEM), in which we aimed at comparing covariations among traits between core and edge

219 populations. Hence, SEM can only be performed with a categorical co-variable (i.e., southern

220 vs. northern) and not with a continuous co-variable (i.e., latitude). Nonetheless, we also ran

221 supplementary analyses (i.e., linear mixed models) with latitude as a continuous variable, and

222 the results were similar (ESM B). Overall, we ran six models in order to test whether the environment (range location and/or temperature) can affect phenotypic traits. For larval darkness, the mean grey value corrected for the control blank was included as a dependent variable, range location, larval size, and temperature of the second behavioral trial (i.e., to control for an effect of temperature on coloration since pictures were taken after the second behavioral trial at either $19{ }^{\circ} \mathrm{C}$ or $25^{\circ} \mathrm{C}$; Garcia et al. 2003; Fedorka et al. 2013) as fixed factors, and the population ID as random intercept. For larval activity, the dependent variable was the activity level of individuals for both temperatures (i.e., two values per individual) and full models included range location, larval size, testing temperature $\left(19^{\circ} \mathrm{C}\right.$ vs. $\left.25^{\circ} \mathrm{C}\right)$, and its interaction with range location as fixed effects to test the variation of behavioral plasticity with range location. Larval ID, population ID, arena ID, and testing order (first vs. second trial) were added as random effects. Larval size variation was tested with range location as a fixed effect and population as a random effect. Models that tested variation in adult darkness and relative thorax length included range location, adult size, sex, and its interaction with range location as fixed effects, and populations as a random effect. Finally, for adult size, the model included range location, sex, and its interaction with range location as fixed effects and populations as a random effect. The interaction between range location and sex was included since in dragonflies females and males can differ in their life-history traits and responses to environmental conditions, including temperature and parasitism (De Block and Stocks 2003),

241 and therefore, in their responses to range expansion (Hughes et al. 2007). Larval or adults 
sizes were added as a covariate when analyzing larval and adult traits since body size often influences morphological, physiological, and behavioral traits (Bonner 2006). across testing temperatures was assessed using linear mixed models with larval ID as a random intercept. Intraclass correlation coefficients $\left(\mathrm{ICC}=\right.$ Variance $_{\text {inter }} /$ Variance $\left._{\text {total }}\right)$ were calculated, and likelihood ratio tests were used to assess the significance of larval ID. Repeatability was scored in the overall dataset and in the separate subsets of southern and northern larvae, to verify the consistency of repeatability across range locations. Standard errors in trait values for each population were quantified as measures of within-population variability, and Mann-Whitney U-tests were used to evaluate differences in variability between the southern and northern populations. Activity (scored as total distance moved) was log-transformed, and all continuous variables were standardized (mean: 0, SD: 1) before the start of the statistical analyses. These analyses were performed using SAS@ v.9.4.

\section{Phenotypic covariation in southern and northern individuals}

257 Structural equation modeling (SEM) was used in order to test: 1) the presence of phenotypic covariation among larval traits, 2) the presence of phenotypic covariation among adult traits, 3) the presence of carry-over effects from larval to adult traits, and 4) the differences in these covariations and carry-over effects between southern and northern populations.

262 (Oberski 2014, R Core Team 2013) with parameters estimated by robust maximum

263 likelihood, and population included as a hierarchical effect. Due to mortality in the larval stage, sample sizes for adult traits were smaller than for larval traits. Traits were scaled to the mean within each range location before running the models. We ran a model that included all covariations (i.e., bidirectional paths) among the three larval traits, but no paths from each 
larval trait to each adult trait. The default model was the model with equal covariances

268

269

270

271

272

273

274

275

276

277

278

279

280

281

282

283

284

285

286

287

288

289

290

291 between the southern and northern populations for all paths. First, we compared this model with a model with all unconstrained covariances to investigate whether matrices of covariances were, on average, different between southern and northern populations. Second, we compared the default model to each alternative model with one covariance unconstrained to be equal between southern and northern populations. Alternative models for which $\triangle \mathrm{AIC}>$ $2\left(\right.$ where $\left.\Delta \mathrm{AIC}=\mathrm{AIC}_{\text {default model }}-\mathrm{AIC}_{\text {alternative model }}\right)$ have substantial support compared to the default model. The goodness of fit of the alternative and default models were compared with likelihood ratio tests. We obtained a final model by selecting unconstrained covariances that improved the AIC compared to the default model. The adequate fit of the final model was tested using chi-square tests, and estimates were derived from this model. The same approach was used to test covariation among adult traits (size, darkness, and relative thorax length). Third, we added unidirectional paths from each larval morphological trait to each corresponding adult morphological trait (larval size and darkness to adult size, relative thorax length, and darkness) to the final model, while covariances between larval and adult traits were fixed based on the final model. The steps for unidirectional paths from larval to adult traits were similar to those of larval covariations.

\section{Results}

\section{Phenotypic differentiation between southern and northern populations}

We found that northern larvae were darker than southern larvae, while larvae from southern and northern populations were similar in body size (Table 1a, Fig. 1). The activity was not different between southern and northern larvae (Table 1a, Fig. 1). However, note that when measuring the alternative measure of risk-taking behavior, we found that northern individuals were bolder than southern individuals (see ESM C for details on the alternative measure of 
risk-taking behavior). Regarding the plastic response of activity to temperature, while the activity was repeatable across testing temperature $\left(\mathrm{ICC}=0.40, \chi^{2}=26.17, \mathrm{P}<0.001\right)$, larvae

were more active at warmer testing temperature. The repeatability was similar in both southern and northern populations $\left(\mathrm{ICC}=0.39, \chi^{2}=12.54, \mathrm{P}<0.001\right.$ and $\mathrm{ICC}=0.40, \chi^{2}=$ $12.54, \mathrm{P}<0.001$ for southern and northern populations, respectively). The strength of this plastic effect did not differ among range locations (Table 1a, Fig. 1, no significant interaction term). None of the traits quantified in adults (adult darkness, adult size, and relative thorax length) differed significantly between southern and northern larvae (Table 1b, Fig. 1). Overall, adult males were darker, larger, and had a greater relative thorax length than adult females (Table 1b, Fig. 1). The between-individual variances for the larval and adult traits did not differ significantly between southern and northern populations (ESM A).

\section{Covariation in larval traits}

The comparison of path models revealed that covariations between darkness and size, and between darkness and activity were different between southern and northern populations (Table 2, Fig. 2a and b). Specifically, larval darkness and activity were positively correlated in the North, while this covariation was not significantly different from zero in southern populations (Fig. 2, ESM D). Larval darkness covaried negatively with larval size in northern populations, while this covariation was not significant in southern populations (Fig. 2, ESM D). However, the difference in covariation was hardly significant, even if it decreased the AIC of the model (Table 2). The final model included differences in covariations between southern and northern populations for larval darkness and activity, and for larval darkness and larval size (Fig. 3). This final model better fitted the data than the default model with all covariances equal among locations (Table 2), and did not differ from the observed covariance matrix $\left(\chi^{2}=1.05\right.$, d.f. $\left.=1, \mathrm{P}=0.31\right)$. 
Covariations among adult traits

319 The covariations among adult traits were also different among range locations (Table 2, Fig.

$3202 \mathrm{c}$ and d). Adult size and darkness were positively correlated in northern populations, while

321 this covariation was not significant in southern populations (Fig. 3, ESM D). On the contrary,

322 adult darkness positively covaried with relative thorax length only in southern populations

323 (Fig. 3, ESM D). The relationship between adult size and relative thorax length did not differ

324 among range locations (Table 2), and was not significant in both southern and northern

325 populations (ESM D). The final model included differences in covariations between southern

326 and northern populations for adult size and darkness, and for adult darkness and relative

327 thorax length (Fig. 3). This model better fitted the data than the default model and did not

328 differ from the observed covariance matrix $\left(\chi^{2}=0.002\right.$, d.f. $\left.=1, P=0.97\right)$.

\section{Carry-over from larval to adult traits}

331 We identified two carry-over effects from larval to adult traits (Fig. 3). Notably, larger larvae emerged into larger adults with a greater relative thorax length (Fig. 3, ESM D). Nonetheless, the larval darkness was not carried-over to adults (Fig. 3). The carry-over effects were not different between southern and northern populations (i.e., none of the directional paths from

335 larval to adult traits differed; Table. 2). The default model was not significantly different 336 from the data $\left(\chi^{2}=7.45\right.$, d.f. $\left.=18, \mathrm{P}=0.99\right)$.

\section{Discussion}

339 Our main results show that phenotypic traits and phenotypic integration (i.e., patterns of trait covariations) were significantly different between southern populations and northern 
morphological traits from larvae to adults are added to the documentation of phenotypic coupling across life stages in organisms with a complex life-cycle (Stoks and Córdoba-

344 Aguilar 2012).

345 Our first expectation was that individuals from populations at the expanding edge were

346 phenotypically different from individuals from core populations due to phenotype-biased

347 founding events or differences in environmental conditions, and the resulting selective

348 pressures, across latitudes. More specifically, we were expecting individuals in northern

349 populations to be more active, darker, larger, and more plastic than individuals in southern

350 populations. Contrary to our expectations, we detected only a difference in larval darkness

351 between southern and northern populations, while there were no differences in body size,

352 activity, and temperature-dependent activity between northern and southern populations.

353 Specifically, larvae from northern populations were, on average, darker than their southern

354 counterparts, which may be explained by several non-exclusive mechanisms. Terrestrial

355 ectotherms often show a gradient of increasing dark coloration with latitude since darker

356 bodies absorb more solar radiation, improving thermoregulation in colder climates (Clusella

357 Trullas et al. 2007; Pinkert et al. 2017). However, caution should be exercised since darker

358 coloration does not always improve thermoregulation in aquatic organisms as water has a

359 much higher specific heat capacity than air (Garcia et al. 2003), and since larval differences

360 in melanism were not carried-over to adults. Alternatively, darker bodies may result from a

361 covariation with unmeasured traits under spatially varying selection. For example, a higher

362 investment in immune function has been observed at higher latitudes (De Block et al. 2008)

363 and at the expansion front in odonates (Therry et al. 2014b), while melanism and immune

364 functions are tightly linked through pleiotropic effects and shared responses to environmental

365 conditions (Côte et al. 2018). Further investigations are needed to investigate these

366 explanations, particularly by measuring the links between darkness, other phenotypic traits, 
and individual fitness with laboratory-raised individuals (i.e., F1 and F2) from different range locations and assessing the relative contribution of plasticity and selection in darkness differentiation.

Our results show that larval traits covaried in northern populations, but this did not occur in southern populations. In northern populations, both positive (between larval darkness and activity) and negative (between larval darkness and larval size) correlations were detected. Variances of trait values did not differ across range locations. Therefore, the lack of covariations among traits in southern populations was not driven by a smaller variability in phenotypic traits. Nonetheless, unmeasured traits, which can underpin trait covariations (i.e., a common causal parent), can vary differently across the range expansion gradient and, in turn, modify the covariations among traits. The adaptive value of covarying traits depends on the selective pressures acting on a population. For example, behavioral correlations between activity, exploration, and aggressiveness were present in three-spined stickleback populations that live sympatrically with predators but were absent in relaxed predator-free populations (Dingemanse et al. 2007). In our current study system, although we have no evidence that predator communities consistently differ between southern and northern habitats, enhanced predation risk is expected in northern populations given the shorter growth season and the associated faster life-history in high latitude populations. In those populations with high predation risk, active animals are likely to gain a large fitness benefit by investing in antipredator strategies. In contrast, less active individuals can benefit from an 'energy-saving' strategy, whereby investment in costly traits is avoided, explaining the positive covariation between activity and darkness in northern populations. Melanin is indeed costly to synthesize and may be included in a trade-off with other costly traits (Roff and Fairbairn 2013, Côte et al. 2018), which could explain the negative covariation between larval darkness and larval size in the northern larvae. Altogether, the observed covariations, between darkness and 
activity and between darkness and body size, may reflect different strategies, where some individuals invested their energy in growth rate to reach larger body size and reproduce faster, while others may invest energy in melanism in order to avoid predators.

Contrary to covariations of larval traits, ontogenetic covariation from larval to adult traits did not differ between southern and northern individuals. Odonata shows a striking habitat shift through metamorphosis, from an aquatic larval stage to a terrestrial adult stage, so it is unlikely that environmental stressors experienced in the larval stage predict stressors in the adult stage. The lack of common environmental stressors that cover both life stages probably eliminates the environmental impact of correlational selection on ontogeny. Larger larvae emerged into larger adults with a greater relative thorax length, which is in line with other studies (Stoks and Córdoba-Aguilar 2012). The size of adults largely determines adult fitness. For example, larger animals have higher survival (Marden and Rowan 2000), and the size in females is closely related to fecundity (Cordero 1991). Thorax size is fixed in adults and determines the maximum space available for flight muscles. Therefore, it determines flight power output (Schilder and Marden 2004) and impacts sexual selection, predator avoidance, and dispersal (De Block and Stoks 2007; Córdoba-Aguilar 2008). Interestingly, the covariation between body size and darkness was reversed in adults with larger individuals being darker only in northern populations (see Fig. 3 and 4). Phenotypic differences between adult males and females from different range locations could have primarily explained the

411 covariation between size and darkness. Males were larger and darker than females, and these

412 differences were more pronounced in northern populations (Fig. 2). However, the size-

413 darkness covariation was not canceled by the addition of a sex effect in a linear model $(\mathrm{P}=$ 414 0.04). Another explanation could be that adult darkness, which was not carried over from the 415 larval to the adult stage, reflects different color hues produced by different pigments 416 (Futahashi 2016), with different physiological constraints (e.g., oxidative stress) and different 
417 functions (e.g., reproduction instead of camouflage). To sum up, further investigations are

418 required to better understand the carry-over of traits in dragonflies and other taxa with

419 metamorphosis and their adaptation to changing environments.

420 Phenotypic integration is increasingly being studied to understand the evolutionary and

421 ecological implications of trait variation among populations living in heterogeneous

422 environments (Beckerman et al. 2010; Therry et al. 2019). Here, we showed the

423 differentiation between core and marginal populations in larval darkness, the covariation in

424 larval behavior and morphology, and the ontogenetic carry-over from larval size to

425 investment in flight morphology. The association of larval size with adult flight morphology

426 and size suggests that constraints at the larval stage only (e.g., season length) also influences

427 phenotypic traits and potentially associated fitness traits at the adult stage. Our results

428 highlight the complex interplay among phenotypic traits of individuals from core and margin

429 populations and emphasize the need for studies to understand the drivers of species'

430 responses to climate change.

431

432 Acknowledgements

433 We kindly thank the people that guided us to populations and helped collecting the samples:

434 Yohan Morizet, Philippe Lambret, Charlotte Sohier, Hajnalka Gyulavári, Diana Goertzen and

435 Frank Suhling. ANB - Belgium, Indre Nature, Grand Port Maritime de Marseille and

436 Département Environnement et Aménagement provided permission and access to

437 populations. This study is part of the project PROBIS (Biodiversa) and financially supported

438 by ONEMA, DFG and SEPA. JC is supported by an ANR-12-JSV7-0004-01. JC and SB are

439 part of the Laboratoire d'Excellence (LABEX) entitled TULIP (ANR-10-LABX-41).

440 Compliance with ethical standards: All applicable institutional and/or national guidelines for

441 the care and use of animals were followed. 
442 Conflict of interest: The authors declare they have no conflict of interest.

\section{References}

444 Armitage SAO, Siva-Jothy MT (2005) Immune function responds to selection for cuticular 445 colour in Tenebrio molitor. Heredity 94:650-656. doi: 10.1038/sj.hdy.6800675

446 Aubret F, Shine R (2009) Genetic assimilation and the postcolonization erosion of phenotypic 447 plasticity in island tiger snakes. Curr Biol 19:1932-1936. doi: 10.1016/j.cub.2009.09.061

448 Bauhus S (1996) Funde von Crocothemis erythreae (Brullé) und Aeshna affinis 449 (Vanderlinden) in der Lippe-Aue (Anisoptera: Libellulida, Aeshnidae). Libellula 15:7945084.

451 Beckerman AP, Petchey OL, Morin PJ (2010) Adaptive foragers and community ecology:

452 linking individuals to communities and ecosystems. Funct Ecol 24:1-6. doi:

$453 \quad 10.1111 / \mathrm{j} .1365-2435.2009 .01673 . \mathrm{x}$

454 Bell AM, Sih A (2007). Exposure to predation generates personality in threespined sticklebacks (Gasterosteus aculeatus). Ecol Lett 10:828-834. doi: 10.1111/j.14610248.2007.01081.x

457

458

459

460

461

462

463

464

465

466

Benke AC (1970) A method for comparing individual growth rates of aquatic insects with special references to the Odonata. Ecology 51: 328-331. doi: 10.2307/1933673

Bonner JT (2006) Why size matters: from bacteria to blue whales. Princeton Univ. Press.

Brockaus T, Roland H-J, Benken T et al. (2015) Atlas der libellen Deutschlands (Odonata).

$$
\text { Libellula Supplement 14:1-394. }
$$

Brodie E (1989) Genetic correlations between morphology and antipredator behavior in natural-populations of the garter snake Thamnophis ordinoides. Nature 342:542-543. doi: $10.1038 / 342542 \mathrm{a} 0$

Brodin T (2009) Behavioral syndrome over the boundaries of life-carryovers from larvae to adult damselfly. Behav Ecol 20:30-37. doi: 10.1093/beheco/arn111 
467 Carere C, Gherardi F (2013) Animal personalities matter for biological invasions. Trends $468 \quad$ Ecol Evol 28:5-6. doi: 10.1016/j.tree.2012.10.006

469 Chen IC, Hill JK, Ohlemuller R, et al (2011) Rapid range shifts of species associated with 470 high levels of climate warming. Science 333:1024-1026. doi: 10.1126/science.1206432 471 Chevin L, Lande R, Mace GM (2010) Adaptation, plasticity and extinction in a changing 472 environment: towards a predictive theory. PloS Biology 8:1-8. doi: $473 \quad$ 10.137/journal.pbio.1000357

474 Chuang A, Peterson CR (2016) Expanding population edges: theories, traits, and trade-offs. 475 Glob Change Biol 22:494-512. doi: 10.1111/gcb.13107

476 Clusella Trullas S, van Wyk JH, Spotila JR (2007) Thermal melanism in ectotherms. J Therm 477 Biol 32:235-245. doi: 10.1016/j.jtherbio.2007.01.003

478 Cordero A (1991) Fecundity of Ischnura graellsii (Rambur) in the laboratory (Zygoptera: 479 Coenagrionidae). Odonatologica 20:37-44

480 Córdoba-Aguilar A (2008) Dragonflies and damselflies: model organisms for ecological and 481 evolutionary theory. Oxford Univ Press.

482 Cote J, Clobert J, Brodin T, et al (2010) Personality-dependent dispersal: characterization, 483 ontogeny and consequences for spatially structured populations. Philos Trans R Soc B484 Biol Sci 365:4065-4076. doi: 10.1098/rstb.2010.0176

485 Cote J, Bestion E, Jacob S, Travis J, Legrand D, Baguette M (2017) Evolution of dispersal 486 strategies and dispersal syndromes in fragmented landscapes. Ecography 40:56-73. doi: $487 \quad 10.111 /$ ecog.02538

488 Côte J, Boniface A, Blanchet S, Hendry AP, Gasparini J, Jacquin L (2018) Melanin-based 489 coloration and host-parasite interactions under global change. Proc Roy Soc B. 285(1879) 
490

491

492

493

494

495

496

497

498

499

500

501

502

503

504

505

506

507

508

509

510

511

512 Endler J (1995) Multiple-trait coevolution and environmental gradients in guppies. Trends

De Block M, Slos S, Johansson F, Stoks R (2008) Integrating life history and physiology to understand latitudinal size variation in a damselfly. Ecography 31:115-123. doi: 10.1111/j.2007.0906-7590.05313.x

De Block M, Stoks R (2007) Flight-related body morphology shapes mating success in a damselfly. Anim Behav 74:1093-1098. doi: 10.1016/j.anbehav.2007.01.023

De Block M, Stoks R (2003) Adaptive sex-specific life history plasticity to temperature and photoperiod in a damselfly. J Evol Biol 16: 986-995.

Debecker S, Sommaruga R, Maes T, Stoks R (2015) Larval UV exposure impairs adult immune function through a trade-off with larval investment in cuticular melanin. Funct Ecol 29:1292-1299. doi: 10.1111/1365-2435.12435

Deknijf G (1995) Crocothemis erythraea en Cercion lindenii, nu al in België en binnenkort ook in Nederland algemeen? Libellennieuwsbrief 4:7-12.

Dijkstra K-DB (2006) Field guide to the dragonflies of Britain and Europe. British Wildlife Publishing.

Dingemanse NJ, Wright J, Kazem AJN, et al (2007) Behavioral syndromes differ predictably between 12 populations of three-spined stickleback. J Anim Ecol 76:1128-1138. doi: $10.1111 / \mathrm{j} .1365-2656.2007 .01284 . x$

Dommanget JL (1987) Etude faunistique et bibliographique des Odonates de France. Secrétariat Faune/Flore Paris.

Endler J (1991) Variation in the appearance of guppy color patterns to guppies and their predators under different visual conditions. Vision Res 31:587-608. doi: 10.1016/00426989(91)90109-I Ecol Evol 10:22-29. doi: 10.1016/S0169-5347(00)88956-9 
514 Fedorka KM, Copeland EK, Winterhalter WE (2013) Seasonality influences cuticle

515 melanization and immune defense in a cricket: support for a temperature-dependent

516 immune investment hypothesis in insects. J Exp Biol 216:4005-4010. doi:

$517 \quad 10.1242 / \mathrm{jeb} .091538$

518 Futahashi Ryo (2016) Color vision and color formation un dragonflies. Curr Opin Insect Sci

519 17:32-39. doi: 10.1016/j.cois.2016.05.014

520 Garcia TS, Straus R, Sih A (2003) Temperature and ontogenetic effects on color change in

521 the larval salamander species Ambystoma barbouri and Ambystoma texanum. Can J Zool-

522 Rev Can Zool 81:710-715. doi: 10.1139/Z03-036

523 García-de-Lomas J, Vilà M (2015) Lists of harmful alien organisms: Are the national

524 regulations adapted to the global world? Biol Invasions 17:3081-3091. doi:

$525 \quad 10.1007 / \mathrm{s} 10530-015-0939-7$

526 Gaston KJ (2009) Geographic range limits: achieving synthesis. Proc R Soc B-Biol Sci

527 276:1395-1406. doi: 10.1098/rspb.2008.1480

528 González-Santoyo, Córdoba-Aguilar (2012) Phenoloxidase: a key component of the insect

529 immune system. Entomol Exp Appl 142:1-16. doi: 10.1111/j.1570-7458.2011.01187.x

530 Hardie DC, Hutchings JA (2010) Evolutionary ecology at the extremes of species' ranges.

531 Environ Rev 18:1-20. doi: 10.1139/a09-014

532 Hill JK, Griffiths HM, Thomas CD (2011) Climate change and evolutionary adaptations at

533 species’ range margins. Annu Rev Entomol 56:143-159. doi: 10.1146/annurev-ento-

$534 \quad 120709-144746$

535 Hodgetts RB, O’Keefe SL (2006) Dopa decarboxylase: a model gene-enzyme system for 536 studying development, behavior, and systematics. Annu Rev Entomol 51:259-284. doi:

$537 \quad$ 10.1146/annurev.ento.51.110104.151143 
538 Hughes CL, Dytham C, Hill JK (2007) Modelling and analyzing evolution of dispersal in 539 populations at expanding range boundaries. Ecol Entomol 32: 437-445.

540 Kim S-Y, Velando A (2015) Phenotypic integration between antipredator behavior and

541 camouflage pattern in juvenile sticklebacks. Evolution 69:830-838. doi:

$542 \quad 10.1111 /$ evo.12600

543 Lohr M (2003) Crocothemis erythraea auch in Niedersachsen (Odonata: Libelludlidae).

$544 \quad$ Libellula 22:35-39.

545 Mafli A, Wakamatsu K, Roulin A (2011) Melanin-based coloration predicts aggressiveness

546 and boldness in captive eastern Hermann's tortoises. Anim Behav 81:859-863. doi:

$547 \quad$ 10.1016/j.anbehav.2011.01.025

548 Magnhagen C, Wacker S, Forsgren E, et al (2014) Context consistency and seasonal variation 549 in boldness of male two-spotted gobies. Plos One 9:e93354. doi:

$550 \quad 10.1371 /$ journal.pone.0093354

551 Marden JH, Rowan B (2000) Growth, differential survival, and shifting sex ratio of free-

552 living Libellula pulchella (Odonata : Libellulidae) dragonflies during adult maturation.

553 Ann Entomol Soc Am 93:452-458. doi: 10.1603/0013-8746

554 Oberski, D.L (2014) lavaan.survey: An R Package for Complex Survey Analysis of 555 Structural Equation Models. J Stat Softw, 57(1), 1-27.

556 Ott J (2007) The expansion of Crocothemis erythraea (Brullé, 1832) in Germany - an

557 indicator of climatic changes. In: Tyagi BK (Ed) Biology of dragonflies. Scientific

558 Publishers Jodhpur.

559 Pettit LJ, Greenlees MJ, Shine R (2016) Is the enhanced dispersal rate seen at invasion fronts 560 a behaviorally plastic response to encountering novel ecological conditions? Biol Lett $561 \quad$ 12:20160539. doi: 10.1098/rsbl.2016.0539 
562

563

564

565

566

567

568

569

570

571

572

573

574

575

576

577

578

579

580

581

582

583

584

Phillips BL, Brown GP, Webb JK, Shine R (2006) Invasion and the evolution of speed in toads. Nature 439:803-803. doi: 10.1038/439803a

Phillips BL, Brown GP, Shine R (2010) Life-history evolution in range-shifting populations. Ecology 91:1617-1627. doi: 10.1890/09-0910.1

Pintor LM, Sih A, Bauer ML (2008) Differences in aggression, activity and boldness between native and introduced populations of an invasive crayfish. Oikos 117:1629-1636. doi: 10.1111/j.1600-0706.2008.16578.x

R Core Team (2013) R: A language and environment for statistical computing. Vienna, Austria: R Foundation for Statistical Computing.

Raffard A, Cucherousset J, Prunier JG, Loot G, Santoul F, Blanchet S (2019) Variability of functional traits and their syndromes in a freshwater fish species (Phoxinus phoxinus): The role of adaptive and non-adaptive processes. Ecology and Evolution 9, 2833-2846.

Roff DA, Fairbairn DJ (2012) The evolution of trade-offs under directional and correlational selection. Evolution 66:2461-2474. doi: 10.1111/j.1558-5646.2012.01634.X

Roff DA, Fairbairn DJ (2013) The costs of being dark: the genetic basis of melanism and its association with fitness-related traits in the sand cricket. J Evol Biol 26:1406-1416. doi: $10.1111 /$ jeb. 12150

Schilder RJ, Marden JH (2004) A hierarchical analysis of the scaling of force and power production by dragonfly flight motors. J Exp Biol 207:767-776. doi: 10.1242/jeb.00817

Stamps JA (2007) Growth-mortality tradeoffs and 'personality traits' in animals. Ecol Lett 5: 355-363.

Stoks R, Córdoba-Aguilar A (2012) Evolutionary ecology of Odonata: A complex life cycle perspective. Ann Rev Entomol 57:249-265. 
585 Therry L, Lefevre E, Bonte D, Stoks R (2014a) Increased activity and growth rate in the non586 dispersive aquatic larval stage of a damselfly at an expanding range edge. Freshw Biol $587 \quad$ 59:1266-1277. doi: 10.1111/fwb.12346

588 Therry L, Nilsson-Örtman V, Bonte D, Stoks R (2014b) Rapid evolution of larval life history, 589 adult immune function and flight muscles in a poleward-moving damselfly. J Evol Biol $590 \quad 27: 141-152$. doi: $10.1111 /$ jeb.12281

591 Therry L, Gyulavari HA, Schillewaert S, et al (2014c) Integrating large-scale geographic 592 patterns in flight morphology, flight characteristics and sexual selection in a range593 expanding damselfly. Ecography 37:1012-1021. doi: 10.1111/ecog.00630

594 Therry L, Bonte D, Stoks R (2015) Higher investment in flight morphology does not trade off 595 with fecundity estimates in a poleward range-expanding damselfly. Ecol Entomol 40:133$596 \quad 142$

597 Therry L, Cote J, Cucherousset J, et al (2019) Genetic and environmental contributions to the 598 impact of a range-expanding predator on aquatic ecosystems. J Anim Ecol. doi:

$599 \quad 10.1111 / 1365-2656.12938$

600 True JR (2003) Insect melanism: the molecules matter. Trends Ecol Evol 18:640-647. doi: $601 \quad$ 10.1016/j.tree.2003.09.006

602 Valiente AG, Juanes F, Nunez P, Garcia-Vazquez E (2010) Brown trout (Salmo trutta) 603 invasiveness: plasticity in life-history is more important than genetic variability. Biol 604 Invasions 12:451-462. doi: 10.1007/s10530-009-9450-3

605 Verhoog MD, Breuker CJ, Brakefield PM (1998) The influence of genes for melanism on the 606 activity of the flour moth, Ephestia kuehniella. Anim Behav 56:683-688. doi:

$607 \quad 10.1006 /$ anbe.1998.0801

608 Werner EE, Anholt BR (1993) Ecological consequences of the trade-off between growth and 609 mortality-rates mediated by foraging activity. Am Nat 142:242-272. doi: 10.1086/285537 
610 Zeuss D, Brandl R, Brändle M, Rahbek K, Brunzel S (2014) Global warming favours light611 coloured insects in Europe. Nat Com 5:3874.

612 
Table 1. (a) Linear mixed models testing for the effects of range location (RL: southern vs. northern) and testing temperature (Temp: $19^{\circ} \mathrm{C}$ vs. $25^{\circ} \mathrm{C}$ ) on activity; and testing for the effect of range location on darkness and size in last instar Crocothemis erythraea larvae. We controlled for the temperature of the second behavioral trial (Temp trial 2) when testing larval darkness. (b) Linear mixed models testing for the effects of range location and sex (female vs. male) on darkness, size and relative thorax length in C. erythraea adults. All models included the population nested in range location as random intercept.

\begin{tabular}{|c|c|c|c|c|c|c|c|c|c|}
\hline \multicolumn{10}{|c|}{ a) Larval traits } \\
\hline & \multicolumn{3}{|c|}{ Activity } & \multicolumn{3}{|c|}{ Laval darkness } & \multicolumn{3}{|c|}{ Larval size } \\
\hline & d.f. & $\mathrm{F}$ & $P$ & d.f. & $\mathrm{F}$ & $\mathrm{P}$ & d.f. & $\mathrm{F}$ & $\mathrm{P}$ \\
\hline$\overline{\mathrm{RL}}$ & $1,8.78$ & 0.98 & 0.348 & $1,6.1$ & 7.30 & 0.035 & $1,8.6$ & 2.51 & 0.149 \\
\hline Temp & 1,181 & 14.94 & $<0.001$ & & & & & & \\
\hline $\mathrm{RL} \times \mathrm{Temp}$ & 1,183 & 0.25 & 0.618 & & & & & & \\
\hline Larval size & 1,216 & 1.66 & 0.199 & 1,219 & 3.17 & 0.077 & & & \\
\hline Temp trial 2 & & & & 1,215 & 0.90 & 344 & & & \\
\hline \multicolumn{10}{|c|}{ b) Adult traits } \\
\hline & \multicolumn{3}{|c|}{ Adult darkness } & \multicolumn{3}{|c|}{ Adult size } & \multicolumn{3}{|c|}{ Relative thorax length } \\
\hline & d.f. & $\mathrm{F}$ & $\mathrm{P}$ & d.f. & $\mathrm{F}$ & $\mathrm{P}$ & d.f. & $\mathrm{F}$ & $\mathrm{P}$ \\
\hline$\overline{\mathrm{RL}}$ & $1,10.9$ & 2.66 & 0.131 & $1,8.4$ & 1 & 0.345 & $1,8.1$ & 0.04 & 0.856 \\
\hline Sex & $1,92.4$ & 9.70 & 0.003 & $1,89.6$ & 13.01 & $<0.001$ & $1,91.3$ & 12.90 & $<0.001$ \\
\hline $\mathrm{RL} \times \mathrm{Sex}$ & $1,91.4$ & 0.08 & 0.784 & $1,89.6$ & 0.45 & 0.506 & $1,91.3$ & 2.91 & 0.092 \\
\hline Adult size & $1,95.8$ & 0.35 & 0.556 & & & & 1,96 & 0.93 & 0.338 \\
\hline
\end{tabular}


Table 2. Comparison of the model fit of alternative models (with a single covariance/regression difference between the southern and northern subset) and the default model (all covariances/regressions equal between the southern and northern subset). A pvalue $\leq 0.05$ indicates that the covariation/regression differs between southern and northern populations. (RL: range location; RTL: relative thorax length). A double arrow represents a covariation, while a single arrow represents a directional path.

\begin{tabular}{lllll}
\hline Model & $\chi^{2}$ & P & AIC \\
\hline
\end{tabular}

Covariations among larval traits

a) Default model (all covariances equal between RL)

b) Unconstrained model (all covariances free across RL)

$11.22 \quad 0.011 \quad 1851.5$

c) Single covariance differences of larval traits between RL

$\begin{array}{lllllc}\text { Larval darkness } & \longrightarrow & \text { Larval size } & \mathbf{3 . 0 1} & \mathbf{0 . 0 8 2} & \mathbf{1 8 5 6 . 3} \\ \text { Larval darkness } & \longleftrightarrow & \mathbf{6 . 8 7} & \mathbf{0 . 0 0 9} & \mathbf{1 8 5 2 . 1} \\ \text { Larval size } & \text { Activity } & 2.29 & 0.129 & 1857 \\ \text { d) Final model with unconstrained covariances improving } & 10.20 & 0.006 & 1850.7 \\ \text { AIC compared to default model (in bold) } & \text { Activity }\end{array}$

Covariations among adult traits

a) Default model (all covariances equal between RL)

b) Unconstrained model (all covariances free across RL)

$22.19<0.001$

810.6

c) Single covariance differences of larval traits between RL

$\begin{array}{lrlrrr}\text { Adult darkness } & \longleftrightarrow & \text { Adult size } & \mathbf{1 3 . 7 2} & <\mathbf{0 . 0 0 1} & \mathbf{8 1 4 . 8} \\ \text { Adult darkness } & \longleftrightarrow & \mathbf{1 0 . 2 5} & \mathbf{0 . 0 0 1} & \mathbf{8 1 5 . 1} \\ \text { Adult size } & \longrightarrow & 0.11 & 0.731 & 823.7 \\ \text { d) Final model with unconstrained covariances improving } & 21.93 & <0.001 & 808.6 \\ \text { AIC compared to default model (in bold) } & \text { RTL } & & \end{array}$

Carry-over from larval to adult traits

e) Default model (all covariances fixed, and regression weights equal between RL)

f) Unconstrained model (all regression weights free across RL)

$0.68 \quad 0.995 \quad 1534.4$

g) Single regression weight differences from larval to adult traits between RL

\begin{tabular}{llllll} 
Larval darkness & $\longrightarrow$ & Adult darkness & $<0.01$ & 0.936 & 1525.1 \\
Larval size & $\longrightarrow$ & Adult darkness & 0.05 & 0.814 & 1525.1 \\
Larval darkness & $\longrightarrow$ & Adult size & 0.04 & 0.823 & 1525.1 \\
Larval size & $\longrightarrow$ & Adult size & 0.25 & 0.611 & 1524.9 \\
Larval darkness & $\longrightarrow$ & RTL & 0.11 & 0.738 & 1525.0 \\
Larval size & $\longrightarrow$ & RTL & 0.14 & 0.702 & 1525.0 \\
\hline
\end{tabular}


Figure legends

Figure 1. Activity (a), body darkness (b), and size (c) of Crocothemis erythraea larvae from southern and northern populations. Activity is plotted for both testing temperatures. Darkness (d), size (e) and relative thorax length (f) of females and males of C. erythraea adults from southern and northern populations. Given are means $\pm 1 \mathrm{SE}$ on scaled variables.

Figure 2. Distributions and relationships among larval traits from southern (a) and northern (b) populations, and among adult traits from southern (c) and northern (d) populations. Estimates are obtained using path-analysis. Bold values represent significant covariances $(\alpha=$ 0.05). $\mathrm{RTL}=$ relative thorax length.

Figure 3. Results from path-analysis. Black lines are covariations and regressions that were significant $(\alpha=0.05)$. Non-significant covariations (grey lines) are shown as indications. A double arrow represents a covariation and a single arrow represents a directional path. Symbols indicate the sign of the path coefficient. See ESM D for details on parameter estimates. 

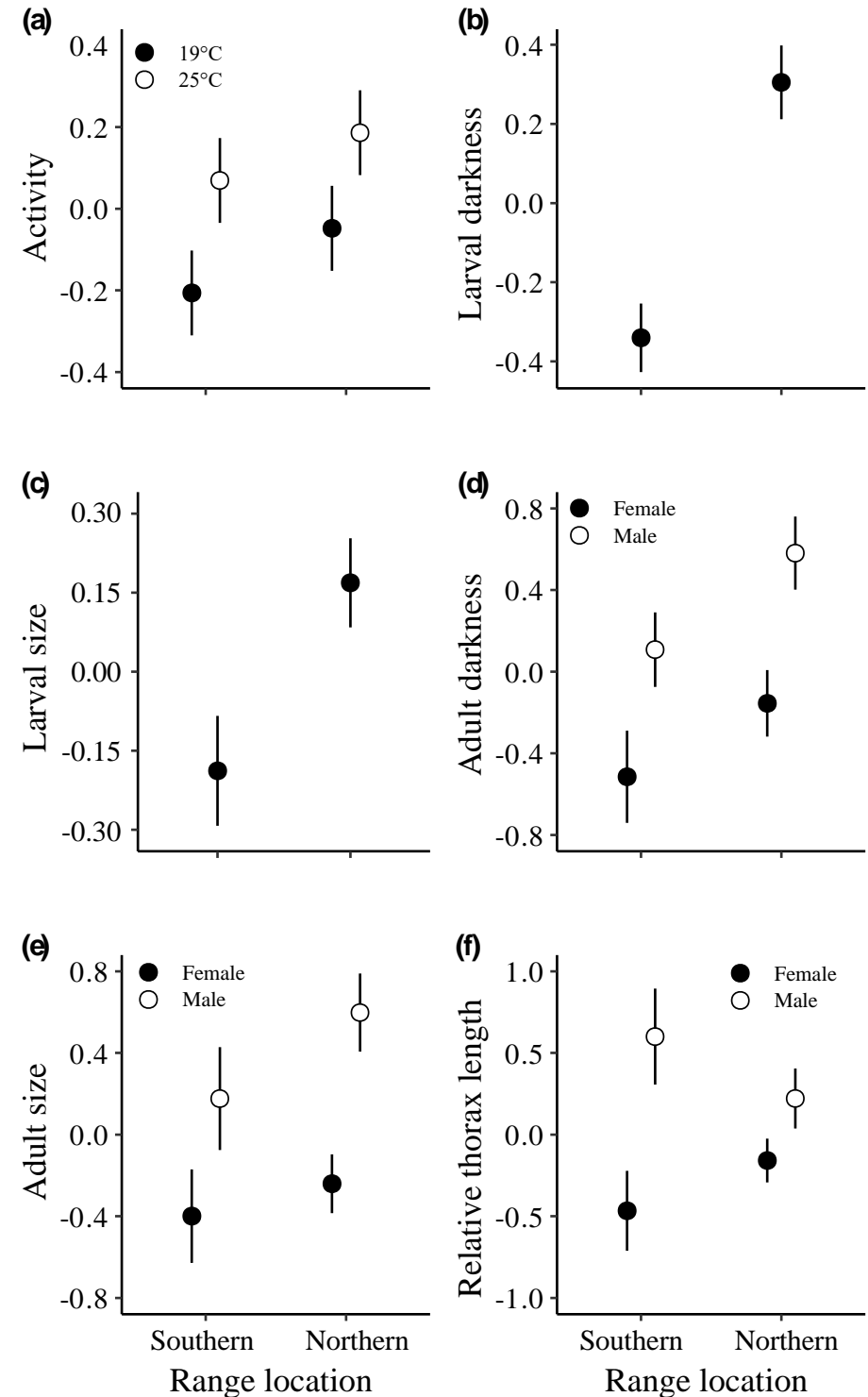

Fig. 1 
(a)

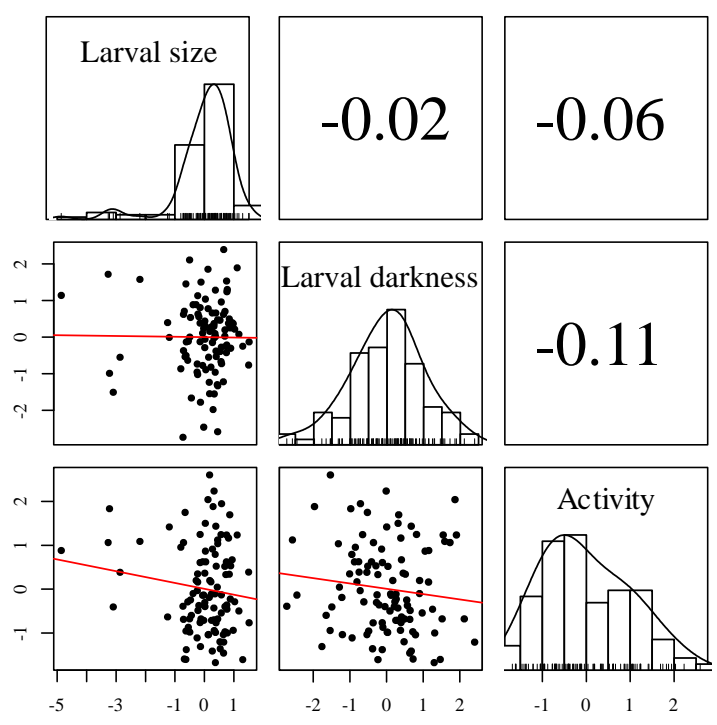

(c)
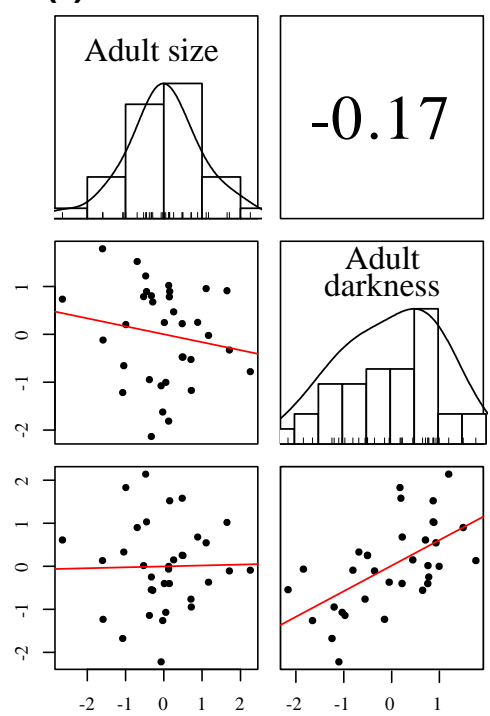

\subsection{3}

(b)

Northern populations
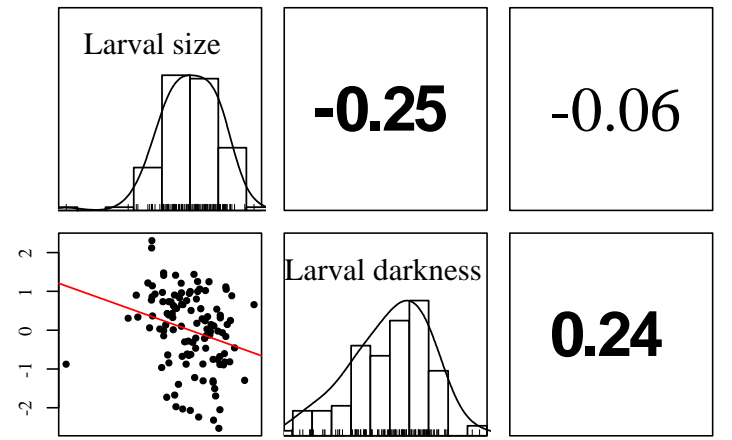

Larval darkness

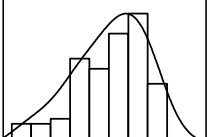

0.24
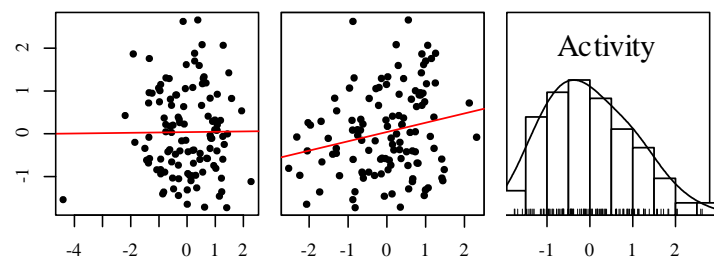

(d)
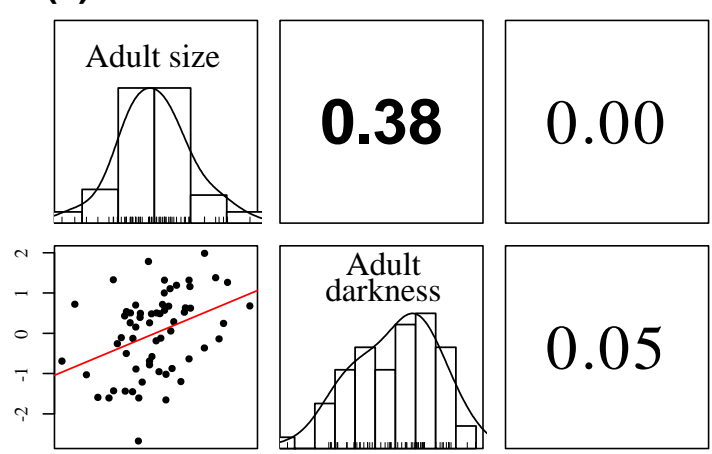

0.05
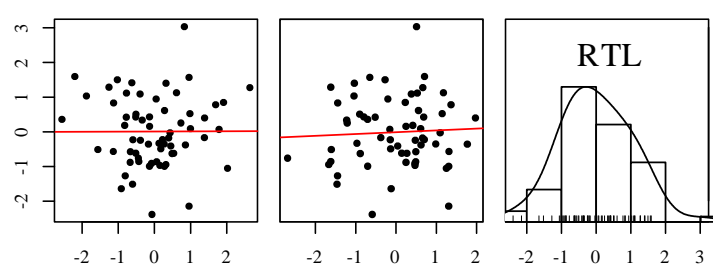

Fig. 2 

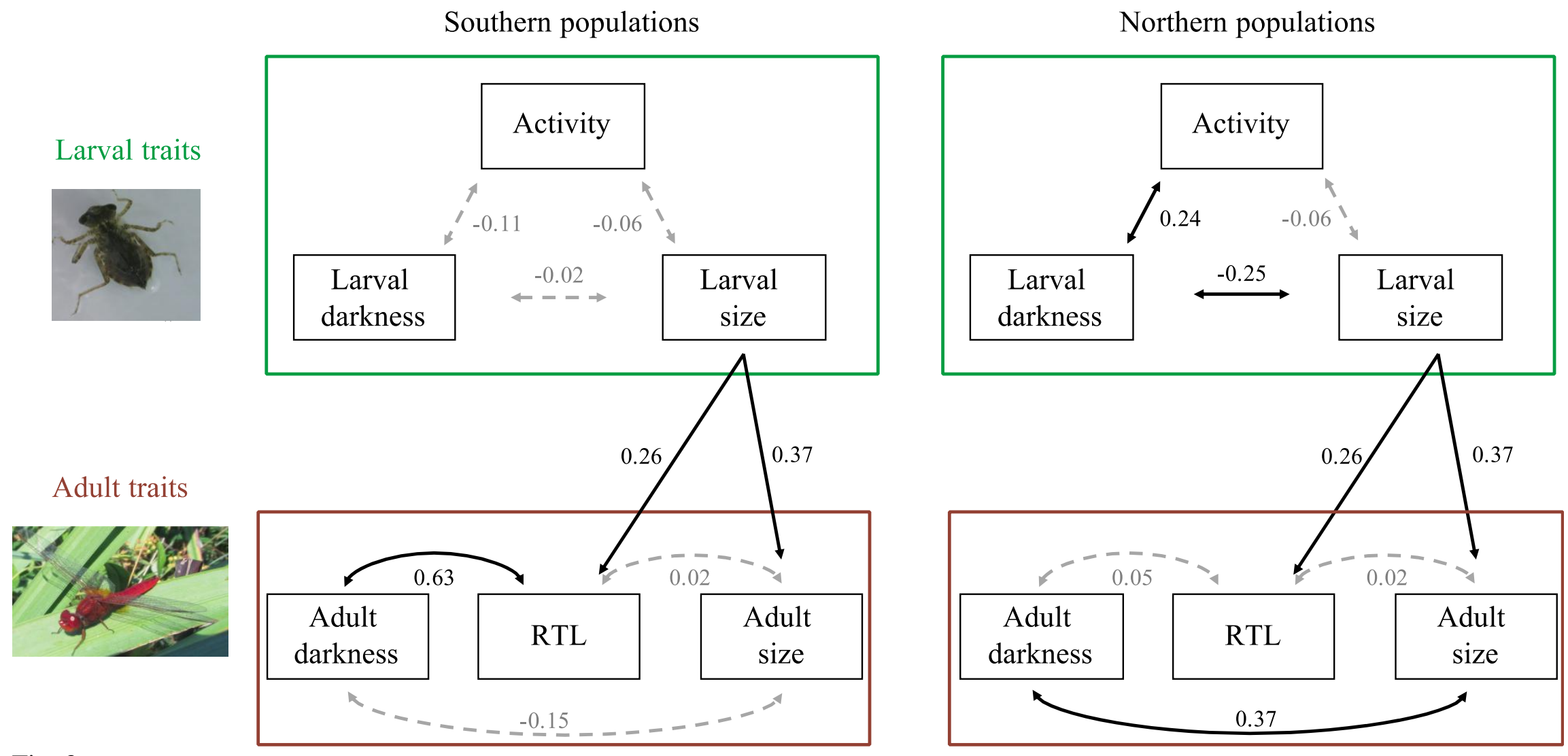

Fig. 3 